\title{
Computational Design and Analysis of a Microtab Based Aerodynamic Loads Control System for Lifting Surfaces
}

C.P. Van Dam, D. Yen Nakafuji, C. Bauer, D. Chao, K. Standish

This article was submitted to

SPIE International Society for Optical Engineers, Photonics West

San Jose, California, January 25-31, 2003

U.S. Department of Energy

Lawrence

Livermore

National

Laboratory

October 31, 2002 


\section{DISCLAIMER}

This document was prepared as an account of work sponsored by an agency of the United States Government. Neither the United States Government nor the University of California nor any of their employees, makes any warranty, express or implied, or assumes any legal liability or responsibility for the accuracy, completeness, or usefulness of any information, apparatus, product, or process disclosed, or represents that its use would not infringe privately owned rights. Reference herein to any specific commercial product, process, or service by trade name, trademark, manufacturer, or otherwise, does not necessarily constitute or imply its endorsement, recommendation, or favoring by the United States Government or the University of California. The views and opinions of authors expressed herein do not necessarily state or reflect those of the United States Government or the University of California, and shall not be used for advertising or product endorsement purposes.

This is a preprint of a paper intended for publication in a journal or proceedings. Since changes may be made before publication, this preprint is made available with the understanding that it will not be cited or reproduced without the permission of the author.

This report has been reproduced directly from the best available copy.

Available electronically at http://www.doc.gov/bridge

Available for a processing fee to U.S. Department of Energy

And its contractors in paper from

U.S. Department of Energy

Office of Scientific and Technical Information

P.O. Box 62

Oak Ridge, TN 37831-0062

Telephone: (865) 576-8401

Facsimile: (865) 576-5728

E-mail: reports@adonis.osti.gov

Available for the sale to the public from

U.S. Department of Commerce

National Technical Information Service

5285 Port Royal Road

Springfield, VA 22161

Telephone: (800) 553-6847

Facsimile: (703) 605-6900

E-mail: orders@ntis.fedworld.gov

Online ordering: http://www.ntis.gov/ordering.htm

\section{OR}

Lawrence Livermore National Laboratory

Technical Information Department's Digital Library

http://www.llnl.gov/tid/Library.html 


\title{
Computational Design and Analysis of a Microtab Based Aerodynamic Loads Control System for Lifting Surfaces
}

\author{
C.P. van Dam ${ }^{1}$, Dora Yen Nakafuji ${ }^{2}$, Candice Bauer ${ }^{1}$, David Chao ${ }^{1}$, and Kevin Standish ${ }^{1}$ \\ ${ }^{1}$ Department of Mechanical and Aeronautical Engineering \\ University of California, Davis, CA 95616 \\ ${ }^{2}$ New Technologies Engineering Division \\ Lawrence Livermore National Laboratory \\ P.O. Box 808, L-644, Livermore, CA 94551
}

\begin{abstract}
A computational design and analysis of a microtab based aerodynamic loads control system is presented. The microtab consists of a small tab that emerges from a wing approximately perpendicular to its surface in the vicinity of its trailing edge. Tab deployment on the upper side of the wing causes a decrease in the lift generation whereas deployment on the pressure side causes an increase. The computational methods applied in the development of this concept solve the governing Reynolds-averaged Navier-Stokes equations on structured, overset grids. The application of these methods to simulate the flows over lifting surface including the tabs has been paramount in the development of these devices. The numerical results demonstrate the effectiveness of the microtab and that it is possible to carry out a sensitivity analysis on the positioning and sizing of the tabs before they are implemented in successfully controlling the aerodynamic loads.
\end{abstract}

Keywords: Fluid Dynamics, Aerodynamics, Active Flow Control, Airfoil, Wing, Rotor, MEMS, Microtab

\section{INTRODUCTION}

The sliding microtab consists of a small tab that emerges from a wing approximately perpendicular to its surface in the vicinity of the trailing edge. Several microtabs arranged in a spanwise array generate a change in the surface pressures and, as a result, a change in the lift, L. In contrast to the simple flap-type device that is currently used to control the aerodynamic load on lifting surfaces and consist of a separate rotating surface that occupies the aft 20 - $30 \%$ of the chord of the lifting surface, the microtab only extends about one percent of the chord. Figure 1 compares the conventional rotating flap device and the sliding microtab that is the subject of our study. In addition to being small, the microtab based control system requires little power to activate, can be manufactured in bulk using conventional microfabrication techniques, and can be implemented without significant changes in existing techniques used to manufacture aircraft wings and tail surfaces or rotor blades on wind turbines and helicopters.

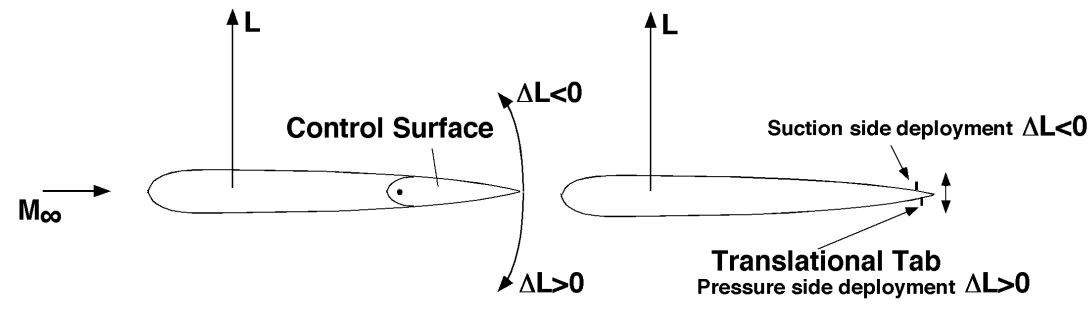

Conventional

Present

Fig. 1 Conventional rotating flap-type and sliding microtab lift control system.

Yen and Van Dam [1,2] first considered the concept of aerodynamic load control by means of sliding microtabs in the trailing-edge regions of lifting surfaces. From the onset of the project, computational fluid dynamics (CFD) has played a critical role in the development of the sliding microtab concept. Particularly, the application of CFD was spurred by the need to retract the tabs. Given the fact that the trailing edge of a lifting surface needs to be sharp and the resulting negligible volume and lack of structure for tab retraction, it does not come as a surprise that trailing edge tabs have remained fixed since first published by Liebeck [3] in 1976. Our idea was (1) to place the tabs upstream from the trailing edge to gain volume and structure to retract them and (2) to retract the tabs by sliding them instead of rotating. 
The question was how far the tabs could be moved forward without losing their load control effectiveness. CFD allowed us to answer this question before spending any time in the clean room or wind tunnel.

This paper focuses on the CFD tools that have been used to analyze and design the microtabs. Also, the microtabs and their actuation are discussed and the changes in lift that can be achieved by extending the tabs are illustrated. Last, the tools that are being used to evaluate 3-D effects are outlined.

\section{COMPUTATIONAL TOOLS}

This section presents the computational tools that are being used in the current project. The focus is on numerical methods that solve the Reynolds-averaged Navier-Stokes (RANS) equations which govern the viscous fluid flows. First, the pre-processing tool that allows us to construct the grid system on which the equations are numerically solved is introduced. Next, the two RANS solvers extensively used in this project, INS2D and OVERFLOW, are presented. Last, the post-processing tool, FieldView, is briefly outlined.

\subsection{OVERGRID}

The primary grid generation tool used in this study is a program called OVERGRID that was developed by William M. Chan at NASA Ames Research Center [4]. OVERGRID serves as a valuable tool for visualizing, constructing, manipulating, and diagnosing many types of grids and geometries. Computational simulations using structured overset grids typically involve multiple steps and a variety of software modules. A graphical interface called OVERGRID has been specially designed for such purposes. Data required and created by the different steps include geometry, grids, domain connectivity information and flow solver input parameters. The interface provides a unified environment for the visualization, processing, generation and diagnosis of such data. General modules are available for the manipulation of structured grids and unstructured surface triangulations. Modules more specific for the overset approach include surface curve generators, hyperbolic and algebraic surface grid generators, a hyperbolic volume grid generator, Cartesian box grid generators, and domain connectivity pre-processing tools.

The OVERGRID interface belongs to a larger soft-ware package called Chimera Grid Tools (CGT) [5]. The CGT package consists of about 40 independent grid generation and solution analysis modules that run in batch mode, the OVERGRID graphical interface, a suite of scripts that can be used for automating overset-grid computations on complex configurations, and several libraries of common routines shared by the various tools.

\subsection{INS2D}

INS2D was developed by Rogers and Kwak at the NASA Ames Research Center [6,7]. The code solves the incompressible, two-dimensional, Reynolds-averaged Navier-Stokes equations in generalized curvilinear coordinates using the artificial compressibility method of Chorin [8] to couple the velocity and pressure fields. The convective fluxes are upwind differenced using a third-order flux-difference splitting scheme developed by Roe [9] and the viscous fluxes are central differenced in standard second-order form. The resulting equations are solved by implicit linerelaxation sweeps. The code can handle both multi-block patched grids as well as overset Chimera grids and has been applied extensively to analyze flows over single and multi-element airfoils [10-14].

\subsection{OVERFLOW}

OVERFLOW is a three-dimensional, compressible RANS flow solver developed by Buning et al. at NASA [15]. Use of three identical computational planes in the spanwise direction permits the modeling of two-dimensional flows. Steady and time-accurate solutions can be calculated on structured block or Chimera overset grids. In this study, all computations are steady and conducted on Chimera overset grids with a central-differencing block tri-diagonal scheme. Artificial dissipation $\left(2^{\text {nd }}\right.$ order dissipation coefficient: $0.00 ; 4^{\text {th }}$ order dissipation coefficient: 0.04$)$ is used to aid numerical stability.

OVERFLOW includes several zero-, one-, and two-equation turbulence models including two versions of the SpalartAllmaras one-equation turbulence model [16] differing in how transition is specified $[15,17]$. The first version introduces a transition term that regulates the transition from laminar to turbulent flow. Hence, there is no need to artificially suppress turbulence production with an "intermittency" function. In addition, a smooth progression from laminar to turbulent flow is provided at the user-specified transition points. This transition method tends to cause transition to extend over too long a distance; therefore, the second transition model is preferred. The second transition model uses an "intermittency" function, ranging from zero to one, that multiplies the turbulence production term in order to obtain a smooth variation in the flow variables at transition onset. The function is zero upstream of the specified 
transition points, corresponding to a laminar flow region, and scales to unity directly downstream of the transition onset location, corresponding to a turbulent region. The default intermittency function for this model is a short ramp (based on the grid index along the wall).

\section{COMPUTATIONAL SENSITIVITY ANALYSIS}

Baseline section shapes selected for analysis include an airplane wing airfoil, the GU25-5(11)-8, and a wind turbine rotor blade airfoil, the S809. The GU airfoil (Fig. 2a) was developed at the University of Glasgow as one of a series of highlift, low-drag airfoils $[19,20]$. The trailing edge of this airfoil provided significant volume conducive to installation of prototype microtabs for the experimental validation. The $S 809$ (Fig. 2b) belongs to a family of low-drag, constrained maximum lift airfoils for horizontal-axis wind turbine developed at the National Renewable Energy Laboratory (NREL). $[21,22]$.

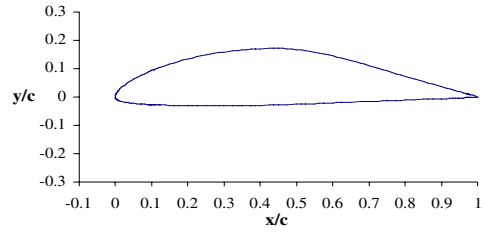

(a) GU25-5(11)-8

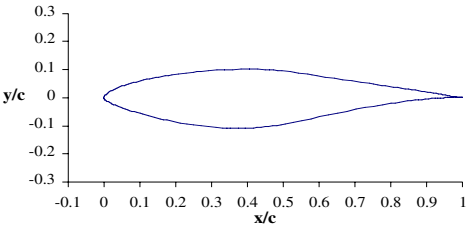

(b) $\mathbf{S 8 0 9}$

Fig. 2 Airfoil section shapes considered in present study.

INS2D was used in the early development stages of the microtab. As mentioned above, one of the key issues was the effectiveness of the tab when moved forward from the trailing edge. Figures 3 show a close-up of the overset grid on which the solutions were computed and a detailed flow solution in the trailing edge region of the GU airfoil for a tab with a height to airfoil chord ratio, $\mathrm{h} / \mathrm{c}$, of $1.0 \%$ placed at the $95 \%$ chord location (i.e., $5 \%$ ahead of the trailing edge). The flow visualization picture clearly shows the separated, recirculating flow behind the tab and the fact that despite the forward location, the tab remains effective. The tab remains effective because the point of flow separation for the entire airfoil has essentially shifted from the airfoil trailing edge to the lower edge of the tab. The change in the location at which the flow leaves the airfoil (Kutta condition) effectively changes the camber of the airfoil and dramatically alters the flow about the entire airfoil without a substantial change in the design of the airfoil.

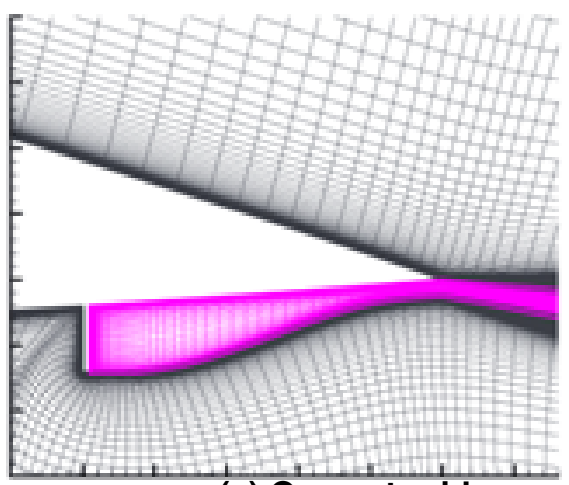

(a) Overset grid

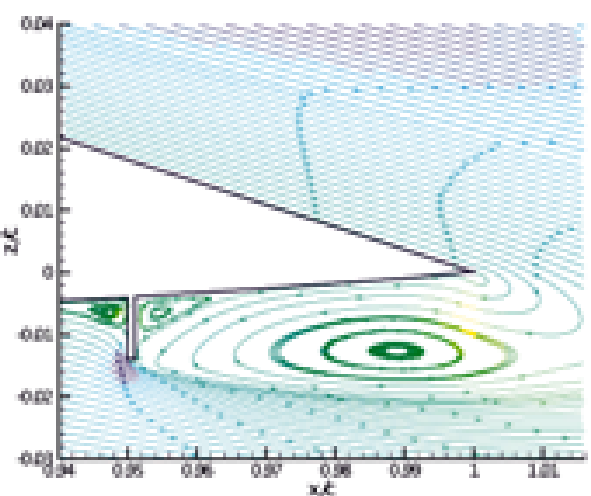

(b) Computed streamlines

Fig. 2 Detail of grid and flow solution for GU airfoil with tab $(\mathrm{h} / \mathrm{c}=0.01)$ at $\alpha=0^{\circ}, \mathrm{Re}=1.0 \times 10^{6}$.

To have sufficient volume for tab retraction, it was necessary to evaluate tab effectiveness for various locations upstream or forward of the trailing edge and for a range of angles of attack. As illustrated in Fig. 3, there is an overall increase in area under the surface pressure curves for tabs placed at the trailing edge as well as upstream locations. The increase in area translates directly to increased lift benefits with the tabs. The resulting pressure coefficient profiles demonstrate that if tabs are located on the pressure side (lower surface), they can generate an increase in lift; however by placing tabs 
on the suction side (upper surface), they can be used to decrease lift. Although results for only $\alpha=0^{\circ}$ are shown in Fig. 3 , this tab effect was observed throughout the angle of attack range.

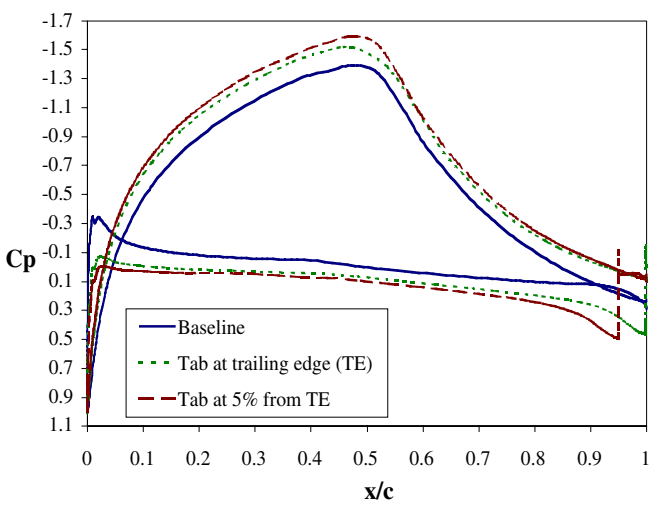

Fig. 3 Computed surface pressure distribution data for baseline GU airfoil and GU airfoil with tabs $(\mathrm{h} / \mathrm{c}=0.01)$ at the trailing edge and $5 \%$ from the trailing edge at $\alpha=0^{\circ}, \mathrm{Re}=1.0 \times 10^{6}$.

The effects of the tabs on lift are summarized in Fig. 4. Note that the computational results show that the tab placed at the trailing edge changed the lift coefficient, $\mathrm{C}_{\mathrm{l}}$, from 0.613 (Fig. 4a, clean configuration) to 0.858 (Fig $4 \mathrm{~b}$, tab at trailing edge) at zero angle of attack. The computed $\mathrm{C}_{1}$ trends agree reasonably well with the experimentally observed trends. These experimental results were obtained in the UC Davis wind tunnel after the computational results were made. The tabs used in the experiment were slightly larger (1.1\%) than the computational model (1.0\%) accounting for the slightly higher but comparable experimental results. Based on the computational results shown in Fig. 4b, an "effective zone" for placing the tabs on the test airfoil was determined to range from $2 \%$ to $6 \%$ of chord forward of the trailing edge with maximum $C_{1}$ benefit at around $3 \%$ of chord from the trailing edge $\left(C_{1}=0.928\right)$. As shown in Fig. $4 b$, drag $\left(C_{d}\right)$ initially dropped as the tab is moved from the trailing edge forward $2 \%$ before steadily increasing as the tab is moved further forward. These results show that the tabs were still effective in increasing $\mathrm{C}_{1}$ for tabs positioned as far as $10 \%$ of chord ahead of the trailing edge, however note the tradeoff made in $\mathrm{C}_{\mathrm{d}}$. Similar results were observed for tabs of differing lengths. Tabs over $2 \%$ chord in length did not seem to cause much further benefit in $\mathrm{C}_{1}$ and in fact resulted in a noticeable increase in $\mathrm{C}_{\mathrm{d}}$. A microtab extension length equal to $1 \%$ of chord positioned at $\mathrm{x} / \mathrm{c}=0.95$ (or $5 \%$ from $\mathrm{TE}$ ) provided the best compromise in terms of tab lift effectiveness, drag and trailing edge volume.

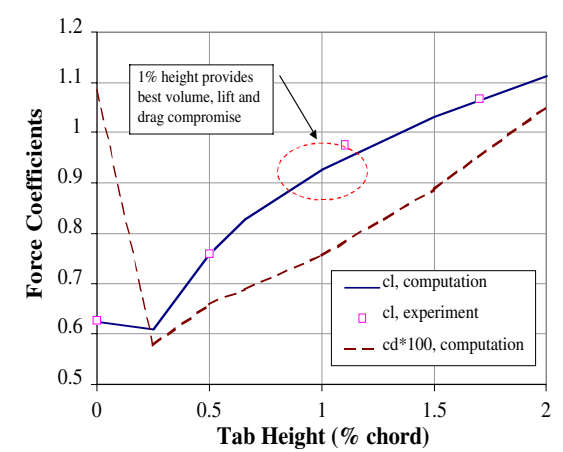

(a)

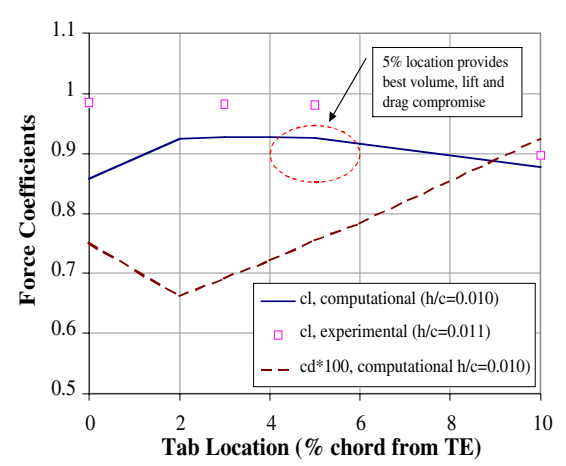

(b)

Fig. 4 a) Effect of tab height (tab at $5 \%$ from trailing edge) and b) effect of tab location (nominal tab height of $1 \%$ ) on force coefficients for airfoil at $\alpha=0^{\circ}, \operatorname{Re}=1.0 \times 10^{6}$.

These computational results provided the impetus to move ahead with the project and fabricate sliding microtabs that could be remotely activated and install these tabs in a wind tunnel model. 


\section{DEVICE}

Throughout the years, trailing edge devices of various geometries and materials have been proposed and studied for the purposes of lift enhancement and control, but many are exploratory and impractical for implementation. For load control applications, robust devices with quick activation and response times, and low installation and maintenance costs are desired. For this project, a two-position ON-OFF device has been conceptualized and fabricated. Initially, mechanical rotating devices as well as flap-like devices were considered; however, the small sizes, the tight interchange ability tolerances, and the total number of devices needed proved to be a manufacturing challenge. Instead, a microfabrication manufacturing approach more suitable to mass production is utilized.

\subsection{Tab Assembly}

As demonstrated in Fig. 5, the tab assembly consists of three pieces: a base, a slider, and an extender. Utilizing the standard microfabrication technique of anisotropic silicon wet etching, excellent precision, a high degree of repeatability, and mass production manufacturing are achieved.

The base and slider are the microfabricated pieces which define the dovetail joint. While almost any single-crystalline material such as gallium arsenide, germanium, quartz, and metal may be used to create the dovetails, the mechanical properties, electronic properties, purity, and etch geometry of $<100>$ silicon is ideal for this application. The dovetail structures are formed using an etching process that is dependent on crystallographic orientation or anisotropic etching.

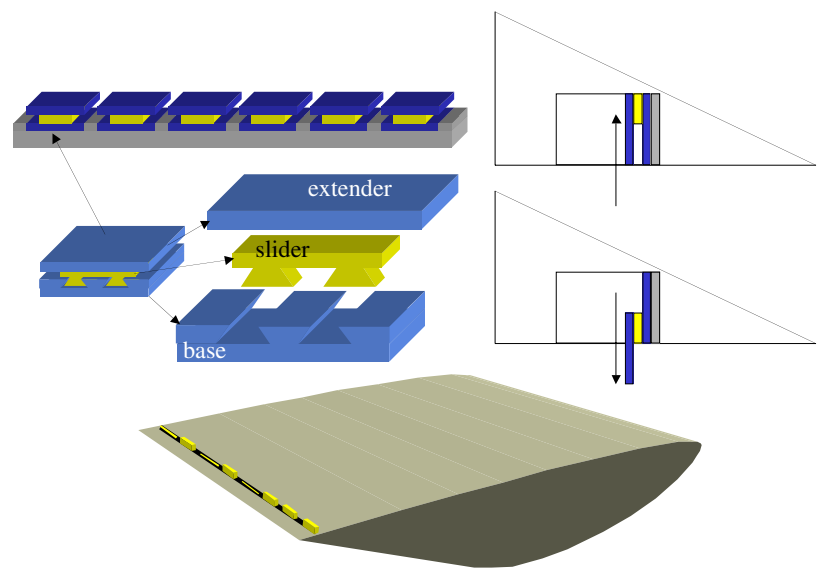

Fig. 5 Three-piece tab assembly consisting of a base, slider, and extender in a modular track assembly. Tab shown in 2-position ON (extended) and OFF (retracted) operation on airfoil pressure side.

Figure 6 illustrates the process flow for the fabrication of the dovetail joint. Using low-pressure chemical vapor deposition (LP-CVD), a silicon nitride etch mask is deposited and patterned on a $<100>$ silicon wafer. Using potassium hydroxide $(\mathrm{KOH})$ at $60 \mathrm{oC}$, the wafer is anisotropically etched to the desired depth. The $<100>$ plane etches 400 times faster than the $<111>$ plane. Because of the differing etch rates for each crystalline orientation, precise dovetail joints with characteristic angles of $54.7^{\circ}$ are formed with a tolerance within $1 \mu \mathrm{m}$ [23]. After the etch is completed, the nitride is stripped. Next, using silicon fusion bonding, the wafer is bonded to a second wafer. The silicon that is exposed is thinned with $\mathrm{KOH}$ to open the dovetails. Finally, the wafers are diced and assembled. 


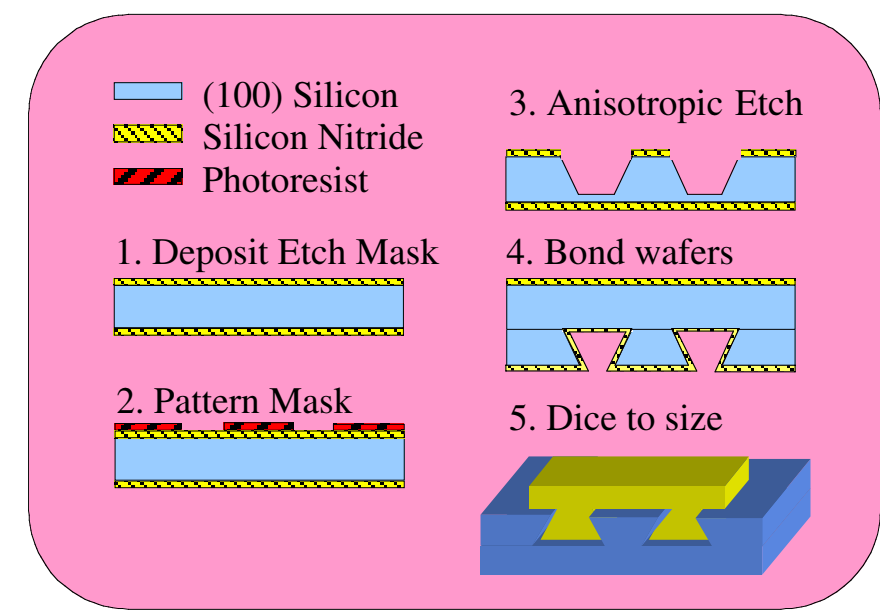

Fig. 6 Process flow for dovetail design used in microtabs.

Great care is taken to fabricate the dovetail joints. The primary issues in this microfabrication process include the precision of the initial mask patterns, timing of the anisotropic etching, and proper alignment of the photo mask to the crystal plane. Prolonged exposure to the $\mathrm{KOH}$ or misaligning the mask will cause undercutting which results in a widening of the dovetail structures. In order to reduce the amount of error, a two-mask process was developed. The first mask consists of using a "wagon wheel" which has etch keys to improve the alignment of the etch masks to the $<110>$ plane. With this technique, the tolerance is within $1 \mu \mathrm{m}$. The alternative process of using a single mask has a tolerance of $\pm 5 \mu \mathrm{m}$.

To complete the tab assembly, the extender is cut to dimensions from a single-sided polished silicon wafer. It is then bonded to the slider. The extender is the only portion of the device that is exposed to the flow. The dovetail structure inherently locks and constrains the slider from unintentional separation. In order to avoid stiction problems, the dovetail joints are coated with $0.1 \mathrm{~mm}$ of LP-CVD silicon nitride. Figure $7 \mathrm{~b}$ shows the final assembly of the microtabs after installation in the wind tunnel model. The total dimensions of each assembly are $20 \mathrm{~mm} \times 5 \mathrm{~mm} \times 1.2 \mathrm{~mm}$. Approximately 30 tab assemblies are needed to cover the wind-tunnel model discussed below. While silicon was utilized in this research project, the design is flexible and allows interchanging a wide variety of materials in future applications [24].

\subsection{Actuation}

For micro-devices, electromagnetic and electro-mechanical systems are predominant due to their minute size and application compatibility. Large electronic, hydraulic, pneumatic, and mechanical systems have been the conventional means of control actuation. Since these controls are continuously exposed to large fluctuating loads and cyclic conditions, they require significant actuation power and tend to be large and heavy. For the microtabs, actuation methods need to first meet extension requirements, $\mathrm{O}(1 \%$ of section chord $)$ as well as activation force, $\mathrm{O}(1 \mathrm{~N}$ depending on tab size). With target voltage limits, cost, space, and weight as additional design constraints, many of the actuation options fail to meet critical design objectives or are considered undesirable for microtab actuation. For example, a design requiring compressed air canisters or hydraulic reservoirs is not desired. High power consumption (high voltage and/or high current) devices are also considered undesirable for microtab actuation.

The overall design goals for the microtabs is to provide a low power, high frequency, lightweight, and quick response actuation system. Currently, several actuation methods are under investigation including thermo-pneumatic, thermal expansion, electro-magnetic, electrostatic, piezoelectric, magnostatic, electrothermo, electromechanical, and shape memory alloy. Unfortunately, none of these meet all of the design criteria specified. Yet, with design improvements, the electro-magnetic and electro-mechanical methods have great potential. This project will continue to investigate the previously developed methods and through the evolution of design, create an innovative actuation system for the microtabs.

\section{VALIDATION OF DEVICE EFFECTIVENESS}

Up to this point the experimental results shown were obtained with fixed (solid) tabs (Fig 7a). The ultimate goal of this study was to demonstrate load control results using remotely activated microtabs depicted in Fig. 7b. Moveable tabs 
were essential to demonstrate the "ON/OFF", on-demand capability and the fact that these microtabs were sufficiently robust to withstand the aerodynamic environment. The tabs were assembled on the test airfoil with a small separation gap for purposes of individual or array actuation and to allow for further work to investigate effects of varying tab shapes and spacing. In Fig. 8 the lift effectiveness of the fixed (solid) tab is compared with that of the remotely activated tabs. Note that results presented in Fig. 8 are for remotely activated tabs with a non-dimensional gap, s/h, of 0.5. This was the smallest gap tested in the wind tunnel and resulted in the highest tab lift effectiveness $\left(\Delta \mathrm{C}_{1}\right.$ change compared to baseline blade section $\mathrm{C}_{1}$ ).

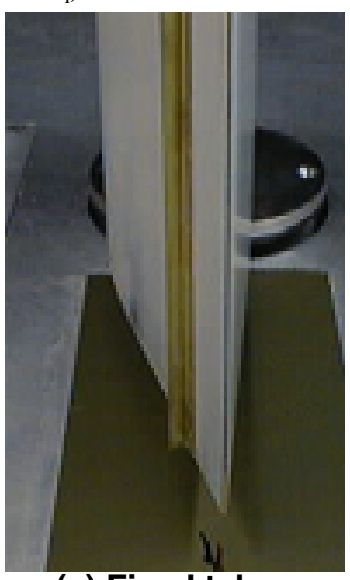

(a) Fixed tab

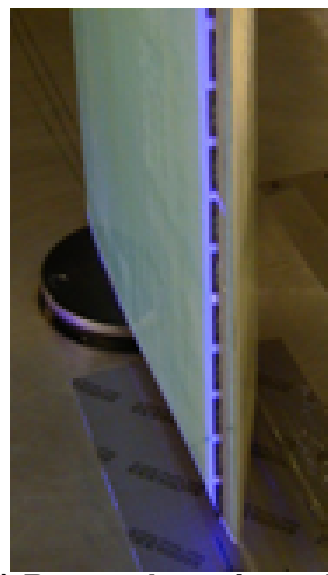

(b) Remotely activated tabs

Fig. 7 Installation of fixed tab at $10 \%$ from the trailing edge and remotely activated microtabs at $5 \%$ from the trailing edge.

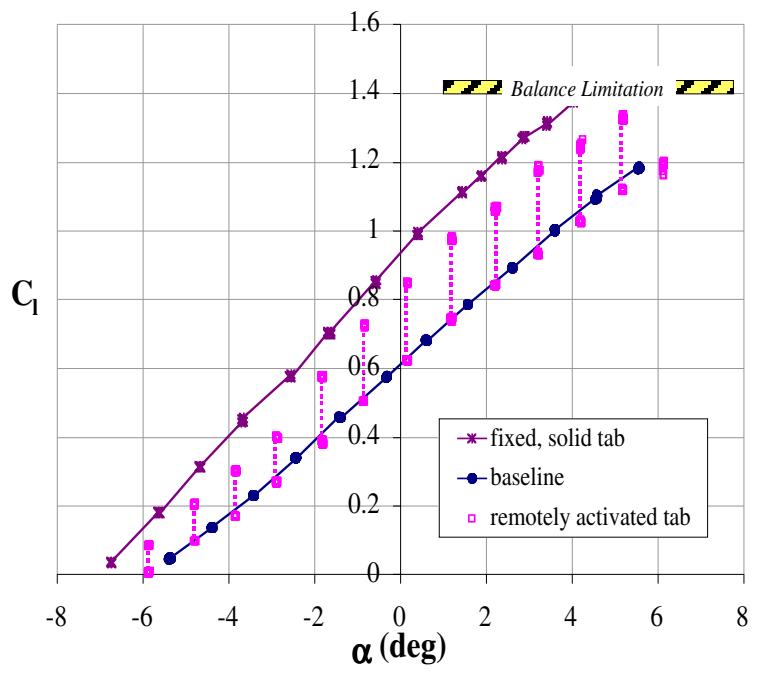

Fig. 8 Comparison of fixed (solid) tab effect and remotely activated tab (tab spacing s/h $=0.5$ ) effect of lift coefficient at $R e=1.0 \times 10^{6}, x_{\text {trans }} / c=0.455$. Tabs at $5 \%$ from trailing edge with nominal tab height of $1 \%$.

Using an electro-mechanical linkage and servo-motor actuation system, the tabs were remotely controllable. Testing demonstrated both microtab robustness and lift enhancement effects. Results from dynamic testing are summarized in Table 1. These results show that a solid tab produces approximately $50 \% \Delta \mathrm{C}_{1}$ enhancement while the $0.5: 1$ microtab is around $42 \%$, the 1:1 microtab gives $33 \%$ enhancement and the $2: 1$ microtab results in $20 \%$ enhancement in lift. This work and earlier reported results demonstrate that, although solid tabs may present the most favorable tab lift effectiveness, tabs with gaps are necessary for actuation and produce some pitching moment and drag reduction benefits. 
Table 1. Summary of lift enhancement effect for various gap spacing with a tab height of $3 \mathrm{~mm}, \alpha=0^{\circ}$.

\begin{tabular}{|l|c|c|c|}
\hline \multicolumn{1}{|c|}{ Setup } & $\begin{array}{c}\text { gap spacing, } \\
\text { [mm] }\end{array}$ & Gap/tab height, s:h & $\mathbf{\%} \mathbf{\Delta \mathbf { C } _ { \mathbf { l } } \text { Enhancement }}$ \\
\hline airfoil, solid tab & 0 & Solid & $50 \%$ \\
airfoil, microtabs & 1.1 & $0.5: 1$ & $42 \%$ \\
airfoil, microtabs & 3 & $1: 1$ & $33 \%$ \\
airfoil, microtabs & 6 & $2: 1$ & $20 \%$ \\
airfoil, no tab & -- & $\infty: 1$ & $0 \%$ \\
\hline
\end{tabular}

The work thus far clearly demonstrates the benefits of combining CFD with experimental wind tunnel testing in a study such as this. While the detailed evaluation and validation of lift and drag tradeoffs must be experimentally made, numerical studies, which are less expensive and quicker to perform, can be used to perform tradeoff studies and narrow the scope of the experimental work to the most promising configurations.

\section{CURRENT EFFORTS}

Further numerical and experimental research needs to be conducted to fully explore the benefits of the microtabs. Although the lift enhancement effects have been demonstrated, research is ongoing to develop an integrated microelectrical-mechanical (MEM) actuation system. Test results show the desired lift enhancement effects may be obtained without adverse moment variations; however, dynamic control and response as well as 3-D microtab gap spacing effects on lift and drag warrant further investigation using a 3-D tool such as OVERFLOW. Current studies using OVERFLOW are looking to validate previous work in 2-D and then to extend the studies to 3-D. Previous work indicated that retaining a slight gap and modifying the tab shape (i.e., serrated shape) may help to decrease overall drag and that continuous solid tabs may not be required for 3-D configurations [25,26]. Recent observations of dragonflies in nature also allude to this fact [27]. Optimizing the gap sizing between microtabs may provide a way to increase lift without significant drag penalties. Two-dimensional and three-dimensional grid development and simulation work is in progress to explore and analyze various tab shape and tab spacing configurations (Fig. 9). Steady as well as time accurate scenarios are expected to yield deeper understanding of the aerodynamic load response capabilities using the microtabs.

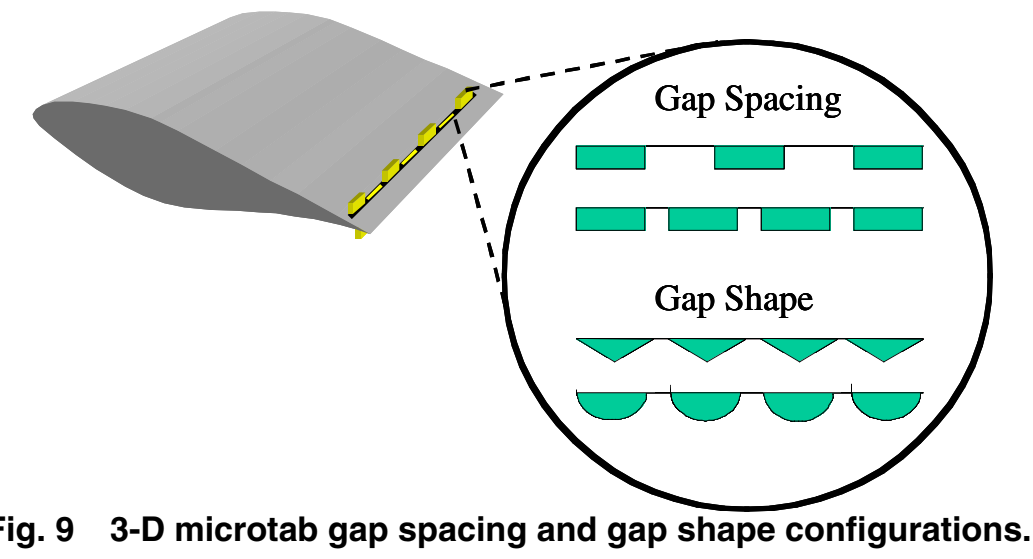

\subsection{Three Dimensional}

Simulations using OVERFLOW are aimed at addressing the following issues: 1) insight into tab gap and downstream wake effects, 2) tab effects on drag reduction, 3) gap spacing and gap shape parameters and 4) time accurate response frequencies.

Initial 3-D overset grids have been generated using OVERGRID. Figure 10 show the baseline airfoil defined using 3 grids, the front box grid, C-mesh for the airfoil and a fanned wake grid. Preliminary results (Fig. 11) show that the 3grid approach provides a balance in maximizing grid resolution and computational efficiency by minimizing grid points. 1 


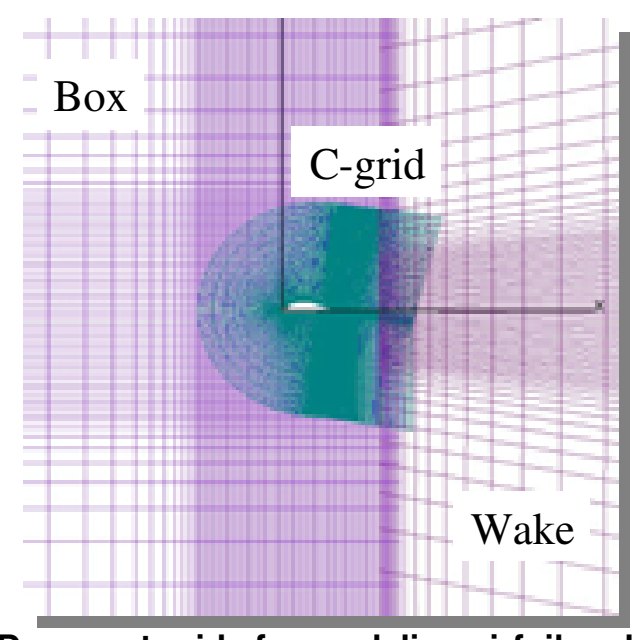

Fig. 10 3-D overset grids for modeling airfoil and microtabs.

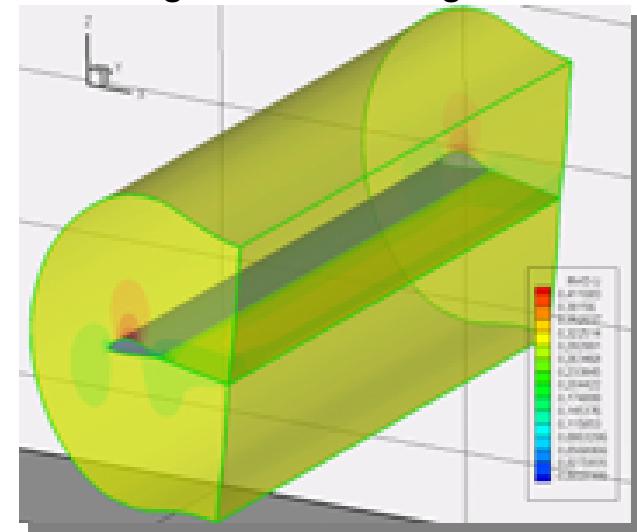

Fig. 11 Preliminary 3-D airfoil simulations using OVERFLOW.

Figure 12 depicts details for the microtab grid. Using a tab cap and tab collar and an embedded wake aft of the tab, the additional grids and clustered points should provide sufficient resolution to capture the details of the vortices and wake interactions. Simulations using the Chimera grid approach and a partial span airfoil with 2 full rectangular tabs and 2 half tabs at the boundary interfaces are currently underway.

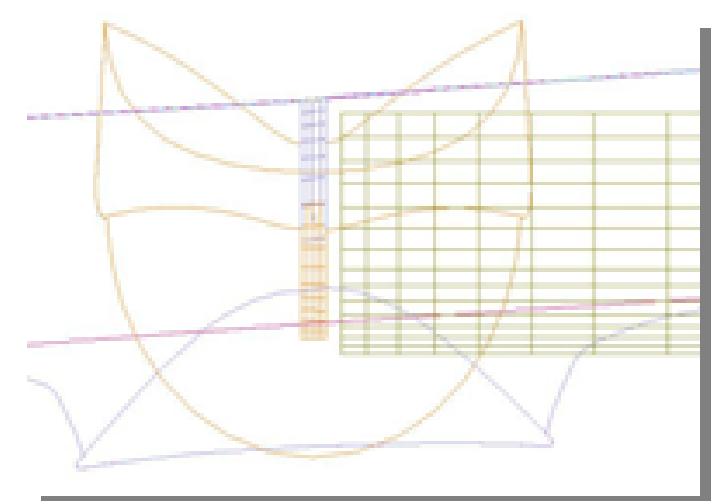

Fig. 12 Chimera grids for the microtab. 


\section{CONCLUDING REMARKS}

The design attributes resulting from the computational fluid dynamics analysis have allowed the sizing and positioning of the sliding microtab based aerodynamic load control system. These numerical results were paramount to the successful development of this concept and gave us confidence to move forward with the fabrication of the microtabs and the wind-tunnel model. Comparisons of the numerical and the wind-tunnel results have been made and have verified the effectiveness of the microtab as a load control system for lifting surfaces. The next step in the development is to quantify computationally and experimentally 3-D aerodynamic effects such as gap spacing and gap shaping and to develop a robust tab actuation system.

\section{ACKNOWLEDGEMENTS}

The authors gratefully acknowledge the help of Dr. William Chan, NASA Ames Research Center, with the overset grid generation process and Professors Rosemary Smith and Scott Collins, University of California at Davis, with the design and micro-fab of the tabs and their actuation system. Also we would like to thank Lawrence Livermore National Laboratory and Sandia National Laboratories (Dr. Dale Berg, technical monitor) for their financial support.

\section{REFERENCES}

1. Yen, D.T., van Dam, C.P., Bräeuchle, F., Smith, R.L., and Collins, S.D., "Active Load Control and Lift Enhancement Using MEM Translational Tabs," Fluids 2000, AIAA Paper 2000-2422, Denver, CO, June 2000.

2. Yen-Nakafuji, D.T., van Dam, C.P., Smith, R.L. and Collins, S.D., "Active Load Control for Airfoils Using Microtabs," Journal of Solar Energy Engineering, Vol. 123, Nov. 2001, pp. 282-289.

3. Liebeck, R.H., "Design of Subsonic Airfoils for High Lift," Journal of Aircraft, Vol. 15, No. 9, Sept. 1978, pp. 547561.

4. Chan, W.M., "The Overgrid Interface for Computational Simulations on Overset Grids," AIAA Paper 2002-3188, June 2002.

5. Chan, W. M., Rogers, S. E., Nash, S. M., Buning, P. G., and Meakin, R. L., "User's Manual for Chimera Grid Tools, Version 1.6," NASA Ames Research Center, September 2001.

6. Rogers, S. E., and Kwak, D., "An Upwind Differencing Scheme for the Time Accurate Incompressible NavierStokes Equations," AIAA Journal, Vol. 28, No. 2, Feb. 1990, pp. 253-262.

7. Rogers, S. E., and Kwak, D., "An Upwind Differencing Scheme for the Steady-state Incompressible Navier-Stokes Equations," Journal of Applied Numerical Mathematics, Vol. 8, No. 1, 1991, pp. 43-64.

8. Chorin, A.J., "A Numerical Method for Solving Incompressible Viscous Flow Problems," Journal of Computational Physics, Vol. 2, 1967, pp. 12-26.

9. Roe, P.L., "Approximate Riemann Solvers, Parameter Vectors, and Difference Scheme," Journal of Computational Physics, Vol. 43, 1981, pp. 357-372.

10. Rogers, S.E., Wiltberger, N.L., and Kwak, D., "Efficient Simulation of Incompressible Viscous Flow over Single and Multielement Airfoils," Journal of Aircraft, Vol. 30, No. 5, Sept.-Oct. 1993, pp. 736-743.

11. Rogers, S.E., "Progress in High-Lift Aerodynamic Calculations," Journal of Aircraft, Vol. 31, No. 6, Nov.-Dec. 1994, pp. 1244-1251.

12. Cao, H.V., and Kusunose, K., "Grid Generation and Navier-Stokes Analysis for Multi-Element Airfoils," AIAA Paper 94-0748, Jan. 1994.

13. Chao, D.D., and van Dam, C.P., "Airfoil Drag Prediction and Decomposition," Journal of Aircraft, Vol. 36, No. 4, July-Aug. 1999, pp. 675-681.

14. Brodeur, R.R., and van Dam, C.P., "Transition Prediction for a Two-Dimensional Navier-Stokes Solver Applied To Wind-Turbine Airfoils," Wind Energy, Vol. 4, 2001, pp. 61-75.

15. Buning, P.G., Jespersen, D.C., Pulliam, T.H., Chan, W.M., Slotnick, J.P., Krist, S.E., and Renze, K.J., "Overflow User's Manual 1.8s," NASA Langley Research Center, November 28, 2000.

16. Spalart, P.R., and Allmaras, S.R., "A One-Equation Turbulence Model for Aerodynamic Flows," La Recherche Aérospatiale, No. 1, 1994, pp. 5-21.

17. Mayda, E.A., and van Dam, C.P., "Bubble-Induced Unsteadiness on A Wind Turbine Airfoil," Journal of Solar Energy Engineering, Nov. 2002 (in print).

18. FieldView reference

19. Kelling, F.H., "Experimental Investigation of a High-Lift Low-Drag Aerofoil," Aeronautical Research Council CP 1187, Sep. 1968.

20. Galbraith, R.A.McD., "The Aerodynamic Characteristics of a GU25-5(11)-8 Aerofoil for Low Reynolds Numbers," Experiments in Fluids, Vol. 3, 1985, pp. 253-256. 
21. Somers, D.M., "Design and Experimental Results for the S809 Airfoil," NREL/SR-440-6918, January 1997.

22. Wolfe, W.P., Ochs, S.S., "CFD Calculations of S809 Aerodynamic Characteristics," AIAA Paper 97-0973, 1997.

23. Gonzalez, C., Smith, R.L., Howitt, D.G. and Collins, S.D., "MicroJoinery: Concept, Definition, and Application to Microsystem Development," Sensors and Actuators, A, Vol. 66, 1998, pp. 315-332.

24. Yen, D.T., "Active Load Control Using Microtabs," Ph.D. Dissertation, University of California at Davis, March 2001.

25. Vijgen, P.M.H.W., van Dam, C.P., Holmes, B. J. and Howard, F. G., "Wind Tunnel Investigations Of Wings With Serrated Sharp Trailing Edges," Low Reynolds Number Aerodynamics, Lecture Notes in Engineering, No. 54, T. J. Mueller (Ed.), Springer-Verlag, 1989, pp. 295-313.

26. Van Dam, C.P., Yen, D.T. and Vijgen, P.M.H.W., "Gurney Flap Experiments on Airfoil and Wings," Journal of Aircraft, Vol. 36, No. 2, 1999, pp. 484-486.

27. Bechert, D.W., Meyer, R. and Hage, W., "Drag Reduction of Airfoils with Miniflaps. Can We Learn From Dragonflies?," AIAA Paper 2000-2315, June 2000. 
University of California

Lawrence Livermore National Laboratory

Technical Information Department

Livermore, CA 94551

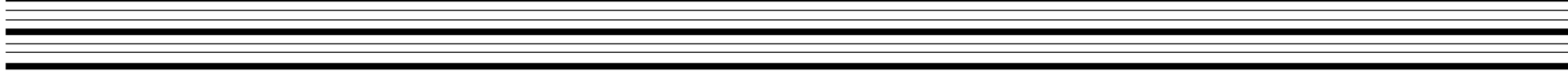

